\title{
Blended cement hydration assessment by thermogravimetric analysis and isothermal calorimetry
}

\author{
Meriem Meziani ${ }^{1}$, Nasser Chelouah ${ }^{1}$, Ouali Amiri ${ }^{2}$, Nordine Leklou ${ }^{2}$ \\ ${ }^{1}$ Laboratoire de Génie de la Construction et d'Architecture, Faculté de Technologie, Université de Bejaia, Algérie \\ ${ }^{2}$ Université de Nantes, GeM, UMR - 6183 CNRS, IUT de Saint Nazaire, France
}

\begin{abstract}
In the present study, the hydration of Portland cement pastes containing 5\%,10\%, 15\% and 20\% tuff, limestone filler and granodiorite was investigated by thermogravimetric analysis coupled with differential scanning calorimetry and microcalorimetry isotherm. The monitoring of the hydration kinetics by thermogravimetric analysis made it possible to quantify the quantity of water combined with the cement (nonevaporable water) and the degree of hydration. By coupling this technique to the differential scanning calorimetry, it was also possible to measure the energy absorbed or released by the material during its decomposition. The results showed that the non-evaporable water content and the degree of hydration of the mixtures containing various mineral admixtures were relatively lower with respect to the reference mixture when as the content of mineral admixture increased. The effect of the evolution of the hydration process on the mechanical properties of mortars was also monitored. The relative variation of the compressive strength to that of the flexural strength was evaluated at 7,28 and 90 days. Results showed that all the mixtures have a greater contribution in flexion than in compression.
\end{abstract}

\section{Introduction}

The constituents of Portland cement undergo a series of chemical and physical processes when mixed with water. The overall process is named as hydration yielding hydrated products. It is known that Portland cement is a multi-component system; therefore its hydration is a rather complex process consisting of a series of individual chemical reactions that take place both in parallel and successively. So, the explanation of its hydration is done, in general, by considering the individual hydrations of the major compounds and their interactions with each other and with other minor phases present in the cement. These considerations affect both the mechanism and the kinetics of hydration. Hydration of Portland cement is affected by a variety of factors such as the compound composition of the cement, the amount of gypsum, fineness, surface area and particle size distribution of the cement, mix composition and cure conditions, presence and amount of minerals and chemical admixtures.

The mechanism and kinetics of the hydration of mineral admixture incorporated cements is of great importance. Some of these materials are considered as inert substances and their effect on hydration is more of a physical nature, some others are of significant chemical reaction with the Portland cement phases. However, mineral admixtures modify the hydration process by both physical and chemical means which are sometimes very difficult to dissociate [1]. Furthermore, the level of the mineral admixtures effect on hydration may fluctuate noticeably, due to the differences in their chemical and mineralogical compositions and physical properties. Study of the hydration process and products in concretes, and even in mortars, is complicated by the presence of the aggregate. But much more detailed information can be obtained from studies on pastes. The hydration of cement is commonly studied using cement pastes which are allowed to hydrate at room temperature.

Although the process of hydration is yet to be fully understood, several modern analytical equipment are being used for the investigation, like transmission electron microscope, scanning electron microscope, quantitative x-ray diffraction, thermogravimetric techniques, conduction calorimetry, and so on.

The progress of the hydration process may be followed by determining the amount of non-evaporable water, determined as the loss on ignition of samples in which free water has been removed first. This method is directly proportional to the degree of hydration and often used as a measure of the fraction of cement that had reacted. The overall kinetics of hydration may be also monitored on the basis of the amount of heat released in the course of hydration.

In this paper, we will restrict our analysis to the examination of the influence of substitution rate and the type of mineral admixture on the performances of the cement pastes and mortars at the hardened state by 
following the evolution of the hydration process (heat and Kinetics of hydration) and its effect on the mechanical properties of mortars.

\section{Materials and mix design}

The cement used in paste and mortar specimens was a commercially available CEM I $52.5 \mathrm{R}$ according to NF EN 197-1 with a specific gravity of 3.14 and a fineness of $440 \mathrm{~m}^{2} / \mathrm{kg}$ [2]. The tuff (T) used is received in bulk and then ground for $20 \mathrm{~min}$ until a fineness of $430 \mathrm{~m}^{2} / \mathrm{kg}$, its specific gravity is 2.66. Limestone (LF) contains $97.30 \%$ of $\mathrm{CaCO} 3$. It is characterized by a fineness of $448 \mathrm{~m}^{2} / \mathrm{Kg}$ and a specific gravity of 2.71 . The granodiorite $(\mathrm{Gr})$ is received in bulk and then crushed and ground for $12 \mathrm{~min}$ until a fineness of $414 \mathrm{~m}^{2} / \mathrm{kg}$, its specific gravity is 2.54 . XRD patterns and SEM image of the mineral admixtures were given in Error! Reference source not found. and Error! Reference source not found.

Blended cements were obtained by direct replacement of a proportion of Portland cement with tuff (T), granodiorite (Gr), or limestone filler (LF). The samples thus obtained were named according to the type and the rate of substitution of the cement by the mineral admixtures. For example, 5T, $5 \mathrm{Gr}$ and $5 \mathrm{LF}$ refer to cements containing $5 \%$ tuff $(\mathrm{T}), 5 \%$ granodiorite $(\mathrm{G})$ and $5 \%$ limestone filler (LF), respectively.
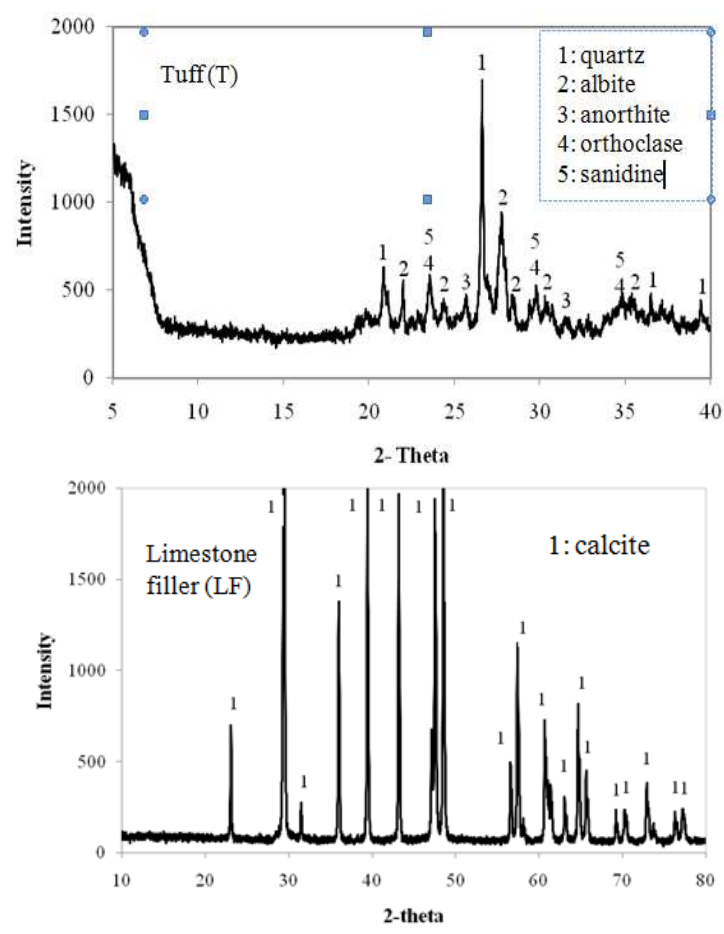

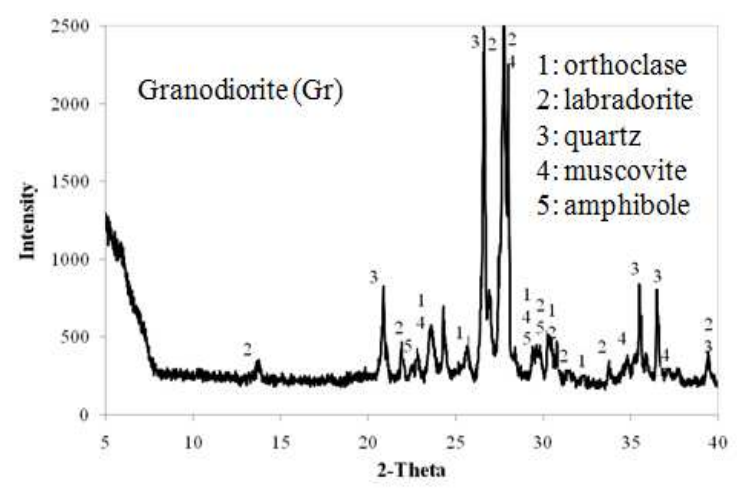

Fig. 1. Caption of the XRD patterns of the mineral admixtures
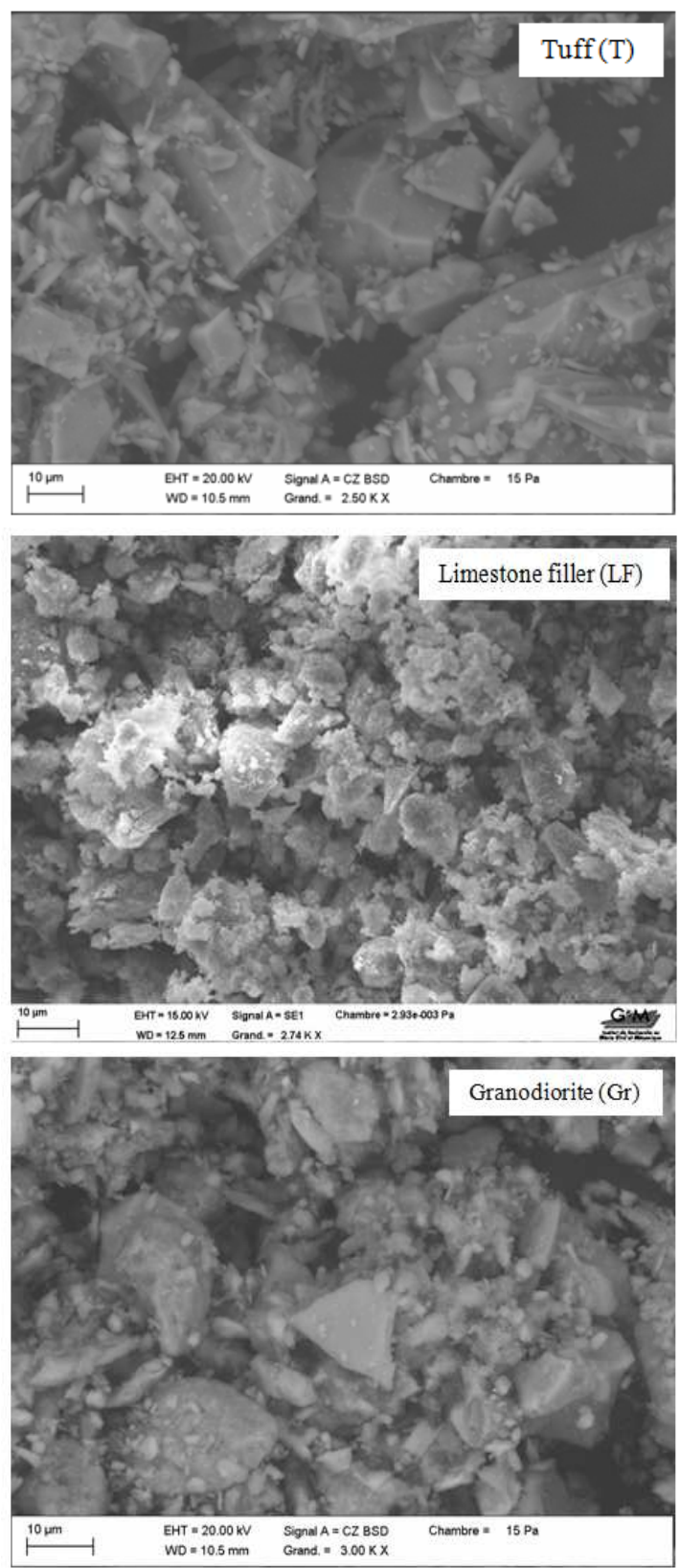

Fig. 2. SEM image of the mineral admixtures

Cement pastes and normalized mortars were formulated with a partially replacing the cement weight with the corresponding percentage of mineral admixture. Five substitution rates were adopted: $0,5,10,15$ and 
20\%. So, 13 mortars and 13 cement pastes were formulated and mixed according to NF EN 196-1 [3] with a mass ratio of water/binder of 0.35 for pastes and 0.5 for mortars. The content of water is kept constant for all formulations, which leads to changes in the rheological properties of the pastes and mortars. The choice of fixing the quantity of water and varying the rheological properties and not the contrary is based on the fact that the second case affects proportionally the initial porosity of the mixtures. This porosity, consequently, will directly influence the development of mechanical resistances.

\section{Techniques of testing}

\subsection{Heat of hydration}

The heat flux due to the hydration reactions of the cement pastes was measured at $20{ }^{\circ} \mathrm{C}$ using a multi-channel isothermal microcalorimeter of TAM Air type interfaced by TA instruments software. After mixing, two samples of each paste were immediately taken from the mixture, placed in bottle, weighed and placed in the microcalorimeter with the reference samples. The heat release of the samples characterizing the reaction rate of the binder was measured automatically in order to quantify the influence of the type of the mineral admixture on the hydration and reactivity of cement at early age in the mixtures.

\subsection{Thermogravimetric analysis of hydration kinetics}

When subjected to high temperatures, the hydration products of the cement decompose releasing water vapor and carbon dioxide. The monitoring and measurement of the different mass losses allowed us to quantify the proportion of water combined with the cement (nonevaporable water) and the degree of hydration. The apparatus used is a Mettler Toledo TGA / DSC 1 type, which measures simultaneously the mass variations of the sample tested and the heat flux between the test sample and a reference crucible. Mass loss calculations and the integration of DTG and heat flux peaks were carried out by the post-processing software associated with the apparatus.

The amount of non-evaporable water and the degree of hydration of the cured cement pastes were determined at 7,28 and 90 days. At each test age, the hardened pastes were further pulverized to assure that all run through the $80 \mu \mathrm{m}$ sieve and then immediately analyzed between room temperature and $1050{ }^{\circ} \mathrm{C}$ at a heating rate of 10 ${ }^{\circ} \mathrm{C} / \mathrm{min}$ in a static air atmosphere.

\subsection{Amount of non-evaporable water and degree of hydration}

Since no drying is carried out, the sample contains both evaporable water and non-evaporable water at the time of the test. The DTG curves show that it is not possible to clearly differentiate the departure of each of the two types of water. It is therefore necessary to define, prior to the analysis of the results, a non-evaporable water evaporation-water boundary temperature. Two temperature values, $105{ }^{\circ} \mathrm{C}$ and $145^{\circ} \mathrm{C}$, were defined as the limit between the end of free water departure and the beginning of hydrate decomposition [4]. In view of the literature, we chose a border temperature of $105^{\circ} \mathrm{C}$.

The amount of non-evaporable water was calculated from the following equation [4]:

$\mathrm{W}_{\mathrm{n}}=L_{d h}+L_{d x}+0,41\left(L_{d c}-L_{d c a}\right)$

$\mathrm{W}_{\mathrm{n}}(\%)$ : Amount of non-evaporable water

$\mathrm{L}_{\mathrm{dh}}(\%)$ : Weight loss between 105 and $400{ }^{\circ} \mathrm{C}$ due to the dehydration of the hydrates

$\mathrm{L}_{\mathrm{dx}}(\%)$ : Weight loss between 400 and $600^{\circ} \mathrm{C}$ due to the dehydroxylation of calcium hydroxide

$\mathrm{L}_{\mathrm{dc}}(\%)$ : Weight loss between 600 et $800^{\circ} \mathrm{C}$ due to the decarbonation of calcite

$\mathrm{L}_{\mathrm{dca}}(\%)$ : Weight loss between 600 et $800{ }^{\circ} \mathrm{C} /$ weight at $105{ }^{\circ} \mathrm{C}$ due to the decarbonatation of anhydrous samples ( $\mathrm{x} \%$ cement $+\mathrm{y} \%$ mineral admixture).

It should be noted that the weight loss is due to both the decarbonation of calcium hydroxide which has been carbonated after the paste has been made, and the carbonation of the anhydrous material.

The degree of hydration is the percentage ratio between the chemically bound water of a given cement paste and that of a fully hydrated paste. The methodology for calculating the degree of hydration from a thermal analysis differs significantly from one researcher to another.

The degree of hydration $\alpha(t)$ of the cement can be calculated from the following equation [5]

$\alpha(\%)=\frac{W n}{W \infty} \times 100$

$\mathrm{W}_{\infty}$ : Water required for a complete hydration of anhydrous cement.

The amount of water required for a complete hydration of anhydrous cement was calculated using the method proposed by S.M. Monteagudo (2014) which is inspired by that of Michaelis-Menten (equation (3)) [4]. The latter is commonly used to calculate the rate of a chemical reaction.

$V=\frac{V m \times s}{\mathrm{~s}+\mathrm{Km}}$

Where $\mathrm{V}$ is the reaction rate, $\mathrm{Vm}$ is the maximum speed, $\mathrm{S}$ is the initial substrate concentration, and $\mathrm{Km}$ is the Michaelis-Menten constant.

Applied to the case studied in this study, the equation would be as stated in equation (4).

$W n=\frac{W \infty \times t}{t+K}$

$\mathrm{t}$ represents the curing time expressed in hours and $\mathrm{K}$ is a constant. To determine the parameters $\mathrm{K}$ and $\mathrm{W} \infty$ numerically, we have used the linearization of equation (4). It is a change of variables that transforms the initial equation into a linear equation, which can then be 
adjusted graphically or by linear regression. The linearization method adopted is that of Lineweaver Burk. This method is considered one of the most accurate in determining the $\mathrm{K}$ and $\mathrm{W} \infty$ characteristics.

In this approach, the constants $\mathrm{K}$ and $\mathrm{W} \infty$ were determined by the representation of their inverses (Lineweaver - Burk representation), which is a straight line with the following equation:

$\frac{1}{W_{n}}=\left(\frac{K}{W \infty} \times \frac{1}{t}\right)+\frac{1}{W \infty}$

\subsection{Flexural and compressive strength}

The mortars were cast in $40 \times 40 \times 160 \mathrm{~mm}^{3}$ metal molds. The mixtures were prepared according to the specifications of NF EN 196-1 [3]. After casting, the molds were stored in a humid chamber for 24 hours at 20 $\pm 1{ }^{\circ} \mathrm{C}$ and at a relative humidity of more than $90 \%$. After 24 hours, the samples were demolded and then stored in the humid chamber. At the age of the test, the specimens were first broken in three-point bending flexural test. The half-prisms resulting from the rupture in flexural test were broken in compressive strength test. The data reported for each mortar represent the average values obtained from three flexural strength tests and six compressive strength tests.

\subsection{Fourier Transform Infrared Spectroscopy (FTIR)}

Fourier Transform Infrared Spectrometry (FTIR) is a method that identifies chemical functions in a product. The wavelengths to which the sample absorbs are characteristic of the chemical groups present in the analyzed material. Infrared analysis measurements were carried out using an IRAFFINITY-1 apparatus between 400 and $4000 \mathrm{~cm}^{-1}$, the scanning number used was 40 and the resolution was $4 \mathrm{~cm}^{-1}$. The traced FTIR spectra were obtained by the KBr pellet technique. The sample of the paste was finely ground and sieved and then mixed with dried $\mathrm{KBr}$, the mixture thus obtained was pressed so as to obtain a pellet as thin as possible so that it is transparent to infrared rays.

\section{Results and discussions}

\subsection{Infrared Spectrometry}

Figure 3 shows the IR spectra of hydrated mixtures containing $20 \%$ of mineral admixtures compared to the parent mixture. A presence of calcium hydroxide marked by the $\mathrm{O}-\mathrm{H}$ vibration at $3640 \mathrm{~cm}^{-1}$, but in the case of $20 \mathrm{LF}$ this band was loss. The vibration intensities at 3415 $\mathrm{cm}^{-1}$ and $1638 \mathrm{~cm}^{-1}$ indicates the formation of calcium silicate hydrates $(\mathrm{C}-\mathrm{S}-\mathrm{H})$. A band at $1114 \mathrm{~cm}^{-1}$ attributed to the formation of ettringite; it should be noticed that in the case of 20LF, the IR spectrum showed a total absence of this band. A wide band located at about $970 \mathrm{~cm}^{-1}$ related to the presence of C-S-H. A triplet at $1455 \mathrm{~cm}^{-1}$, $875 \mathrm{~cm}^{-1}$, and $713 \mathrm{~cm}^{-1}$ characterizing the elongation vibrations of the $\mathrm{C}-\mathrm{O}$ bond present in calcium carbonate (CaCO3). These three bands were accompanied by harmonics at about $2980 \mathrm{~cm}^{-1}, 2875 \mathrm{~cm}^{-1}, 2517 \mathrm{~cm}^{-1}$ and $1797 \mathrm{~cm}^{-1}$.
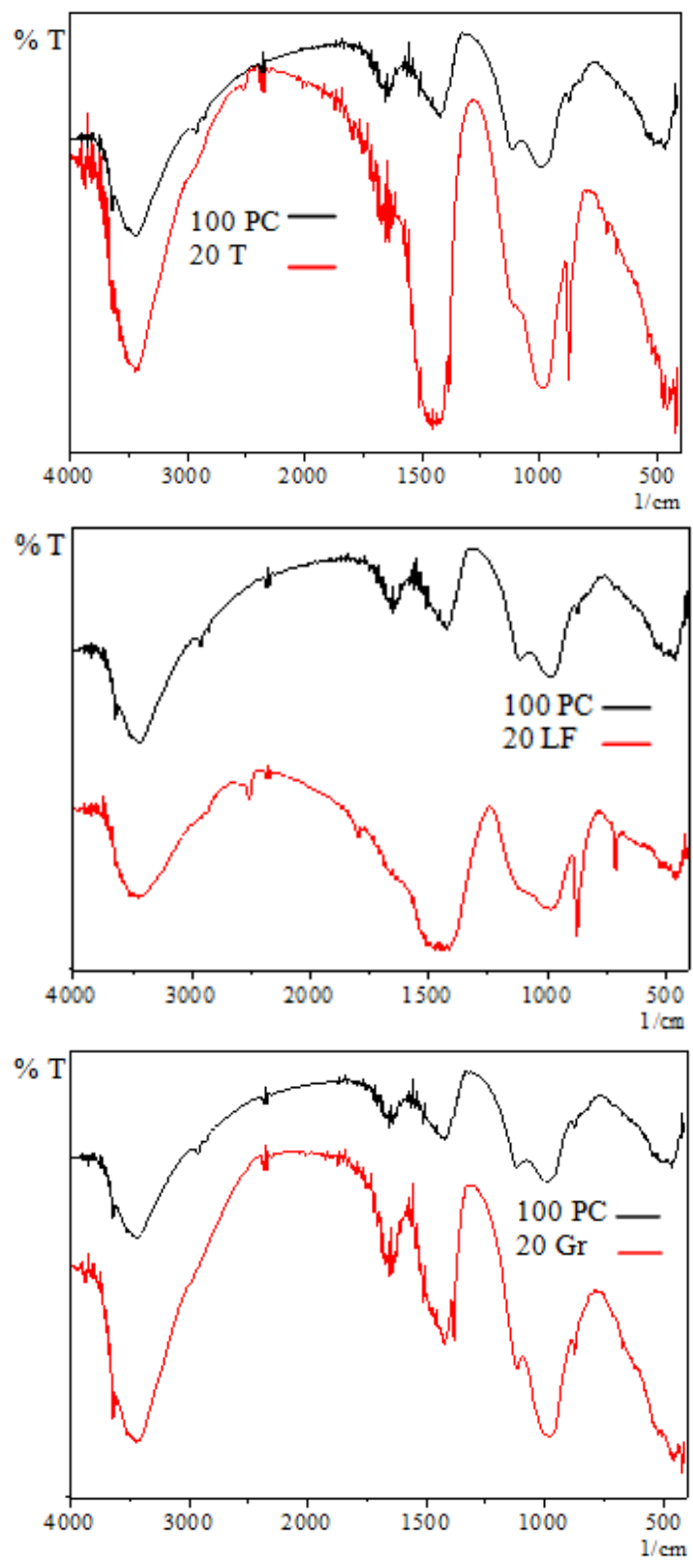

Fig. 3. Infrared spectrometry of the pastes

\subsection{Hydration heat by microcalorimetry}

Table 1 shows that the heat flux at its maximum decreases with the increase of the mineral admixture amount in the binder. The time taken to reach the maximum peak decreases with the increase of the mineral admixture content, but in the case of the LF the appearance of the peak is delayed.

Table 1 shows also the measured values of the total hydration heat released over a period of 72 hours (exper hydr heat) and the hydration heat calculated for a pure cement (calc hydr heat). The calculated heat of hydration was calculated according to the following expression: 


$$
Q_{z \text { alchydrheat }}=\frac{\text { Quever hyl hatal }}{100-\% \text { substitution }} \times 100
$$

An increase in the amount of mineral admixture decreases the experimental hydration heat and reduces the total heat released. The experimental hydration heat of $213.39 \mathrm{~J} / \mathrm{g}$ in the reference paste was reduced to 173.5 $\mathrm{J} / \mathrm{g}, 176.04 \mathrm{~J} / \mathrm{g}$ and $164.72 \mathrm{~J} / \mathrm{g}$ for $20 \%$ replacement of $20 \%$ of cement by LF, Gr and T respectively. As the cement has been partially replaced by the mineral admixtures, this reduction can be attributed to the dilution effect. Indeed, an increase in the rate of mineral admixture is accompanied by a decrease in the cement content, and naturally less cement means less hydration products. This effect is also indicated by M. Tokyay (2016) [1].

If the mineral admixtures used did not have a significant effect on hydration, the heat released in samples containing $20 \%$ of mineral admixtures should be equal to half of $213.39 \mathrm{~J} / \mathrm{g}$; or $106.7 \mathrm{~J} / \mathrm{g}$. This result is fully agree with that of P. Dabic et al (2006)[6]. The limestone filler, which has been considered by several researchers as an inert material, is gradually accepted as contributing to the hydration process by the formation of hydrated calcium monocarboaluminates [7].

If the use of the mineral admixture did not contribute to the release of heat, the hydration heat calculated with pure cement would be $213.39 \mathrm{~J} / \mathrm{g}$, although some samples released higher heat. The increased contribution to heat release is particularly marked with the addition of 15$20 \%$ limestone filler and $20 \%$ granodiorite.

Table 1. Evaluation of the characteristics of the heat flux peak $\left(\mathrm{q}_{\max }\right)$ and the total hydration heat of the different pastes.

\begin{tabular}{|c|c|c|c|c|}
\hline & $\begin{array}{c}\text { Intensity of hydration } \\
\text { peak }(\mathrm{mW} / \mathrm{g})\end{array}$ & $\begin{array}{c}\text { Age of hydration } \\
\text { peak }(\mathrm{h})\end{array}$ & $\begin{array}{c}\text { Experimental hydration } \\
\text { heat at 72h }(\mathrm{J} / \mathrm{g})\end{array}$ & $\begin{array}{c}\text { Calculated hydration } \\
\text { heat at 72h }(\mathrm{J} / \mathrm{g})\end{array}$ \\
\hline $100 \mathrm{PC}$ & 4.92 & 7.76 & 213.39 & 213.39 \\
\hline $5 \mathrm{~T}$ & 4.59 & 7.76 & 186.60 & 196.42 \\
\hline $10 \mathrm{~T}$ & 4.62 & 7.67 & 185.42 & 206.02 \\
\hline $15 \mathrm{~T}$ & 4.49 & 7.53 & 180.94 & 212.87 \\
\hline $20 \mathrm{~T}$ & 4.38 & 7.61 & 164.72 & 205.90 \\
\hline $5 \mathrm{LF}$ & 4.54 & 8.00 & 187.76 & 197.64 \\
\hline $10 \mathrm{LF}$ & 4.53 & 8.04 & 185.25 & 205.83 \\
\hline $15 \mathrm{LF}$ & 4.44 & 8.08 & 182.65 & 214.88 \\
\hline $20 \mathrm{LF}$ & 4.41 & 8.01 & 173.50 & 199.64 \\
\hline $5 \mathrm{Gr}$ & 4.60 & 7.78 & 189.66 & 207.32 \\
\hline $10 \mathrm{Gr}$ & 4.59 & 7.82 & 186.59 & 212.91 \\
\hline $15 \mathrm{Gr}$ & 4.52 & 7.65 & 180.97 & 220.05 \\
\hline $20 \mathrm{Gr}$ & 4.54 & 7.38 & 176.04 & \\
\hline
\end{tabular}

cement matrix resulted in dispersion of the cement particles, thereby reducing the tendency to flocculation and exposing more cement surfaces to hydration. In addition, the dispersion effect leads to a more homogeneous distribution of the water in the cement paste and thus facilitates hydration. However, this effect can be avoided if the mineral admixture is high [9].

Non-evaporable water content is plotted in figures 4-6. The curves have been progressively increased over time but remain below the parent mixture of Portland cement alone at all tests ages. The decrease in the amount of nonevaporable of mixtures containing mineral admixtures was recorded at its maximum for $20 \%$ replacement of cement. At 7 days of age, the decrease was $0 \%, 6.76 \%$ and $6.24 \%$ for mixtures of Tuff, granodiorite and limestone filler, respectively. However, this decrease increases at 28 and 90 days. It reached $6.39 \%, 7 \%$ and $9.74 \%$ at 28 days and $12.27 \%, 11.7 \%$ and $15.46 \%$ at 90 days respectively. The results obtained are probably due to the decrease in the quantity of the cement partially substituted by the mineral admixtures, dilution effect [8]. It should be noted that the 5LF mixture exhibited a higher amount of non-evaporable water than that of the parent mixture. Incorporation of $5 \%$ limestone filler into the

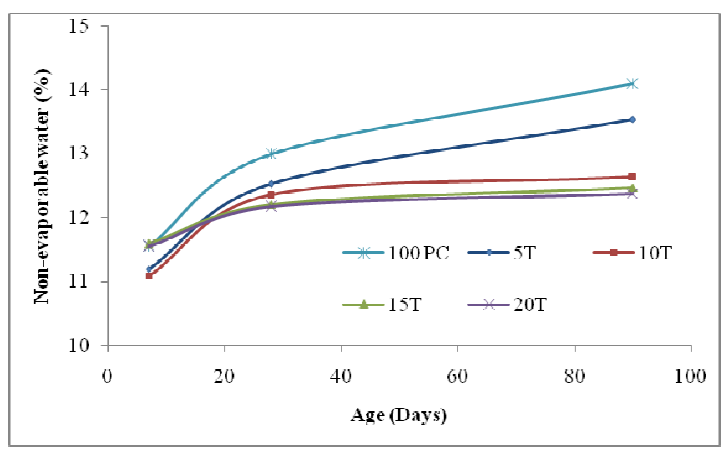

Fig. 4. Non-evaporable water content in the pastes containing tuff 


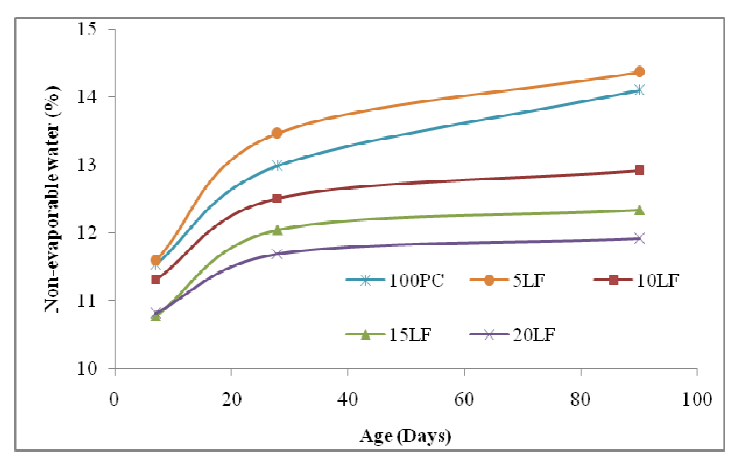

Fig. 5. Non-evaporable water content in the pastes containing limestone filler

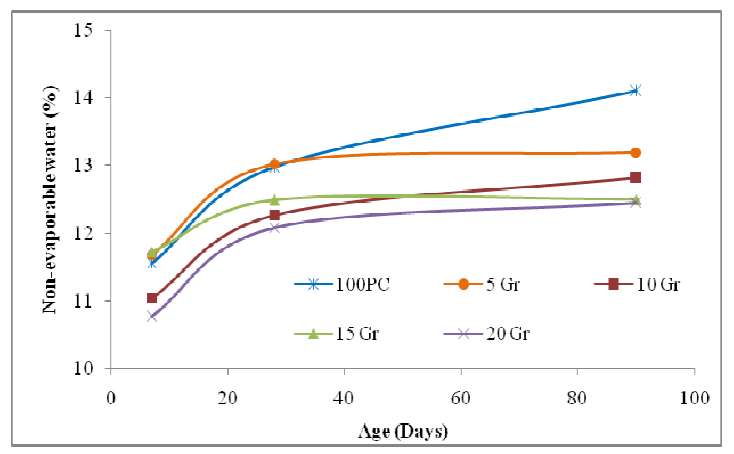

Fig. 6. Non-evaporable water content in the pastes containing granodiorite

\subsection{Degree of hydration}

The degrees of hydration of the pastes were monitored at 7,28 and 90 days and presented in table 2. The degrees showed a gradual evolution over time. They were very high and exceed $100 \%$ in some mixtures at 90 days. This is a direct result of the number of experimental values considered and from the way of obtaining the interpolated curves. Since the last age for tests was 90 days, mixtures for which hydration has not been completed, hydration values above $100 \%$ were obtained because hydration proceeds more slowly and remains in progress. Mixtures containing different percentages of tuff appear to be the most comparable of the parent mixture in terms of degree of hydration.

Table 2. Degree of hydration of the pastes

\begin{tabular}{|c|c|c|c|}
\hline & \multicolumn{3}{|c|}{ Degree of hydration (\%) } \\
\hline & 7 days & 28 days & 90 days \\
\hline $100 \mathrm{PC}$ & 85.15 & 95.78 & 104.02 \\
\hline $5 \mathrm{~T}$ & 85.89 & 96.05 & 103.80 \\
\hline $10 \mathrm{~T}$ & 91.31 & 94.68 & 104.00 \\
\hline $15 \mathrm{~T}$ & 93.33 & 98.24 & 102.40 \\
\hline $20 \mathrm{~T}$ & 85.15 & 96.76 & 100.05 \\
\hline $5 \mathrm{Gr}$ & 86.29 & 96.18 & 97.46 \\
\hline $10 \mathrm{Gr}$ & 81.49 & 94.63 & 96.57 \\
\hline $15 \mathrm{Gr}$ & 91.91 & 96.85 & 96.44 \\
\hline
\end{tabular}

\begin{tabular}{|c|c|c|c|}
\hline $20 \mathrm{Gr}$ & 85.42 & 95.91 & 98.81 \\
\hline $5 \mathrm{LF}$ & 81.43 & 94.61 & 100.94 \\
\hline $10 \mathrm{LF}$ & 87.21 & 96.46 & 99.53 \\
\hline $15 \mathrm{LF}$ & 86.10 & 96.12 & 98.53 \\
\hline $20 \mathrm{LF}$ & 89.98 & 97.29 & 99.15 \\
\hline
\end{tabular}

\subsection{Mechanical strength}

In order to illustrate the similarities and differences between the flexural strength and the compressive strength, we compared the relative variation (relative to the reference mortar) of the compressive strength to that of the flexural strength. From figure 6 it can be noted that replacement of cement by the mineral admixture resulted in less compressive and flexural strength reduction at the early age ( 7 days); but at the latter ages of curing, replacement at $5 \%$ and $10 \%$ produced lower flexural strength improvement. In fact, at 7 and 28 days the tuff mortars line up on the bisector of the diagram. On the other hand, some points diverge from the bisector and present a greater contribution in flexural than in compressive strength namely limestone filler and granodiorite. At 90 days, all the mortars deviate from the bisector and present a greater contribution in flexural than in compressive strength. Similar results were found in the literature [10].
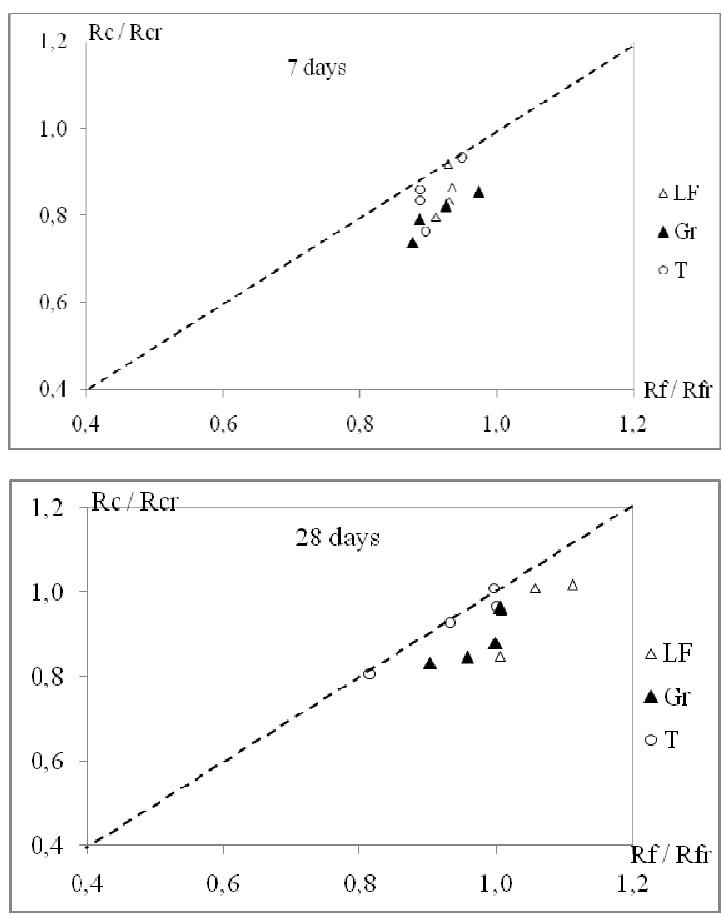


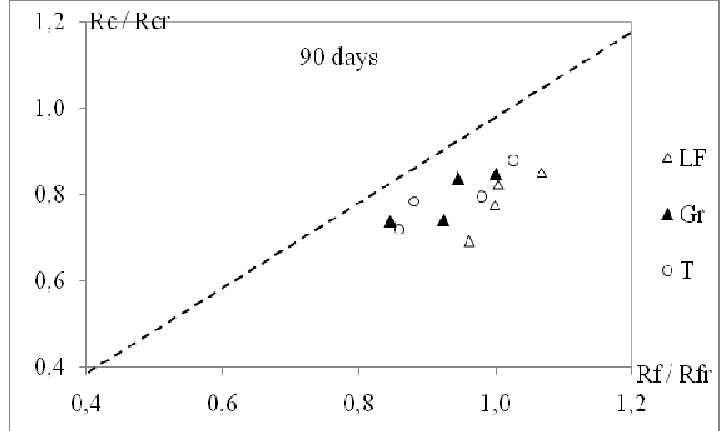

Fig. 6. Relationship between the relative compression and flexural strength of mortars

\section{Conclusions}

This paper presents the influence of the type and level of mineral admixture in the binder on the evolution of the hydration process and its effect on the mechanical properties. From the results obtained the following conclusions can be drown:

The maximum peak of heat flux decreases when the amount of mineral admixture increases. And, the necessary time to reach the maximum peak decreases with the increase of the mineral admixture content, but in the case of the LF the appearance of the peak is delayed.

An increase in the amount of mineral admixture decreases the experimental hydration heat and reduces the total heat released.

The non-evaporable water content and the degree of hydration of the mixtures containing various mineral admixtures were relatively lower with respect to the reference mixture.

The relative variation of the compressive strength to that of the flexural strength showed that all the mixtures have a greater contribution in flexural than in compressive strength.

\section{References}

[1] M. Okyay, Cement and concrete mineral admixtures, CRC Press , 2016.

[2] NF EN 197-1 Ciment- Partie 1: Composition, spécifications et critères de conformité des ciments courants, Comité européen de normalisation, Bruxelles, 2001.

[3] NF EN 196-1 Méthodes d'essais des ciments. partie 1: Détermination des résistances mécaniques, (2006).

[4] S.M. Monteagudo, A. Moragues, J.C. Gálvez, M.J. Casati, E. Reyes, The degree of hydration assessment of blended cement pastes by differential thermal and thermogravimetric analysis . Morphological evolution of the solid phases, Thermochim. Acta. 592 (2014) 37-51.

[5] I. Pane, W. Hansen, Investigation of blended cement hydration by isothermal calorimetry and thermal analysis, Cem. Concr. Res. 35 (2005) 1155-1164.

[6] P. Dabic, P. Krolo, A. Bubic, R. Krstulovic,
Solidification and stabilization of waste zeolite in cement matrix, in: 16.Internationale Baustofftagung, 2006: pp. 483-490.

[7] R. Lewis, L. Sear, P. Wainwright, R. Ryle, Cementitious additions, in: J. Newman, B. Seng Choo (Eds.), Adv. Concr. Technol. Const. Mater., Butterwort, Great Britain, 2003: p. 281.

[8] P. Krolo, R. Krstulovic, D. Pero, A. Bubic, Hydration and leaching of the cement-zeolite composite, Ceram. - Silikaty. 49 (2005) 213-219.

[9] P. Lawrence, M. Cyr, E. Ringot, Mineral admixtures in mortars: Effect of inert materials on short-term hydration, Cem. Concr. Res. 12 (2003) 1939-1947.

[10] C. Poon, L. Lam, S. Kou, Z. Lin, A study on the hydration rate of natural zeolite blended cement pastes, Constr. Build. Mater. 13 (1999) 427-432. 